\title{
BMJ Open Incidence and outcomes of emergency self-harm among adolescents: a descriptive epidemiological study in Osaka City, Japan
}

Tasuku Matsuyama, ${ }^{1}$ Tetsuhisa Kitamura, ${ }^{2}$ Kosuke Kiyohara, ${ }^{3}$ Sumito Hayashida, ${ }^{4}$ Masahiko Nitta, ${ }^{5,6}$ Takashi Kawamura, ${ }^{7}$ Taku Iwami, ${ }^{7}$ Bon Ohta $^{1}$

To cite: Matsuyama T, Kitamura T, Kiyohara K, et al. Incidence and outcomes of emergency self-harm among adolescents: a descriptive epidemiological study in Osaka City, Japan. BMJ Open 2016;6:e 011419 .

doi:10.1136/bmjopen-2016011419

- Prepublication history for this paper is available online. To view these files please visit the journal online (http://dx.doi.org/10.1136/ bmjopen-2016-011419).

Received 5 February 2016 Revised 8 June 2016 Accepted 9 June 2016

CrossMark

For numbered affiliations see end of article.

Correspondence to Dr Tasuku Matsuyama; task-m@koto.kpu-m.ac.jp

\section{ABSTRACT}

Objectives: To evaluate the incidence and outcomes of self-harm from ambulance records.

Design: A retrospective, observational study.

Setting: Osaka City, Japan.

Participants: A total of 365 adolescents aged 10-19 years with emergency self-harm such as poisoning by drugs or gas, cutting skin, jumping from heights, hanging and drowning and treated by emergency medical service personnel from January 2010 through December 2012.

Primary outcome measurements: Incidence per 100000 persons and outcome at the scene or hospital arrival by age and gender. Poisson regression models for incidence evaluation were used; reporting relative risks (RRs) and their $95 \% \mathrm{Cls}$.

Results: During the study period, a total of 425 selfharm events were documented in 365 adolescents. The incidence of self-harm increased significantly between the ages of 11 and 19 years, from 6.3 to 81.0 among boys and the ages of 12 and 19 years from 6.3 to 228.3 among girls, respectively (both $p<0.001$ ). Although there was no incidence difference between girls and boys in the group aged 11-14 years (RR $1.20 ; 95 \% \mathrm{Cl} 0.59$ to 2.47 ), the incidence was significantly higher among girls than boys in the group aged $15-19$ years (RR $4.18 ; 95 \% \mathrm{Cl} 3.20$ to 5.45 ).

The overall proportion of death by self-harm was $4.9 \%$. The proportion of hospital admission and death by self-harm was higher among boys than among girls ( $38.6 \%$ vs $25.2 \%, p=0.016$ and $14.8 \%$ vs $2.4 \%$, $\mathrm{p}<0.001)$.

Conclusions: The incidence of emergency treatment for self-harm by adolescents increased with age and our findings also demonstrated the gender paradox. It would be necessary to establish active, gender-specific and comprehensive prevention strategies for adolescent self-harm, based on our findings showing the age and gender differences of self-harm among adolescents.

\section{INTRODUCTION}

WHO reported that upwards of 800000 people commit suicide all over the world,

\section{Strengths and limitations of this study}

- To the best of our knowledge, this is the first study to assess emergency medical service (EMS)-related adolescent self-harm and provides important epidemiological information which may help prevent incidents of self-harm among adolescents in Asia.

- No other such large-scale evaluations have been conducted using the ambulance records in Asia.

- This study included only emergency patients treated by EMS personnel, and we therefore have no information on walk-ins with self-harm or patients who did not request emergency services.

- We did not obtain information on the purpose/ motivation of self-harm such as suicidal intention.

with one death by suicide every $40 \mathrm{~s}^{1}{ }^{1}$ While the annual suicide incidence decreased from 12.5 to 10.4 per 100000 persons in the 1990s, incidence has been rising again since the $2000 .^{2}$ Suicide is one of the major causes of death in a number of populations, particularly adolescents, and the third leading cause of death among those aged 10-14 years and the leading cause of death among those aged 15-19 years in Japan, ${ }^{3}$ as well as the second leading cause of death among those aged $15-24$ years in the USA. ${ }^{4}$

Self-harm is the strongest risk factor for future suicide. ${ }^{5}{ }^{6} \mathrm{~A}$ number of studies have been conducted on the topic of paediatric self-harm. While incidence of self-harm has been shown to be higher among adolescents than adults, ${ }^{2} 7$ rates of lifetime experience of self-harm vary by community, producing conflicting findings. ${ }^{8}$ For example, where some studies found that women were more likely to have had a self-harm experience than men among adolescents, others noted no significant gender disparities among adolescents. ${ }^{9-11}$ 
Of note, most reports on adolescent self-harm have collected data using interviews of theoretical sampling or from single-centre medical records, but relatively few population-based studies have evaluated the incidence of emergency self-harm and their outcomes treated by emergency medical service (EMS) personnel.

Osaka City is the largest metropolitan community in western Japan, and ambulances are dispatched more than 200000 times every year. Using the ambulance records in Osaka City, we conducted a population-based epidemiological study to provide fundamental information for the prevention of adolescent self-harm.

\section{METHODS}

Study design, population and settings

Our descriptive study retrospectively observed the ambulance records of Osaka Municipal Fire Department from January 2010 through December 2012. All adolescents (aged 10-19 years) treated by EMS personnel for selfharm in Osaka City were included. If two or more incidents of self-harm were confirmed from one adolescent (eg, both cutting skin and poisoning were confirmed simultaneously from one adolescent), each event was treated as an independent case. In this study, self-harm was classified by the EMS/physicians as the following: poisoning by drugs, poisoning by gas, cutting skin, jumping from heights, hanging and drowning according to previous studies. ${ }^{12} 13$ For patients transported to a hospital, the diagnosis of self-harm was clinically confirmed by the physicians caring for the patient after hospital arrival in collaboration with EMS personnel. For patients not transported to any hospital, the diagnosis was made by EMS personnel based on on-site observations and the EMS interview with the patient. Since the personal identifiers were already removed from the database by the EMS personnel, the requirement of informed consent of patients was waived by the Personal Information Protection Law and the national research ethics guidelines of Japan.

\section{EMS system and emergency hospitals in Osaka City}

Osaka City has an area of $222 \mathrm{~km}^{2}$, and the population is 2.7 million in 2010 (population density, about 12000 persons $\left./ \mathrm{km}^{2}\right) .{ }^{14}$ The municipal EMS system of Osaka City is similar to that used in other areas of Osaka Prefecture, as previously described. ${ }^{15}$ The system is operated by the Osaka Municipal Fire Department and is activated by dialling the emergency number ' 119 ' on a telephone. ${ }^{16}$ In 2010 , Osaka City had 25 fire stations (60 ambulances in total) and one dispatch centre. Usually, each ambulance typically operates with a crew of three emergency care providers including at least one emergency life-saving technician, highly trained in providing prehospital emergency care. Osaka City had 186 hospitals (32 922 beds) in 2012, 94 of which-including 6 critical care centres-were equipped to treat patients with life-threatening emergencies. ${ }^{16}$ All patients who requested emergency services were transported to one of these 186 hospitals. During the study period, emergency dispatchers in Osaka City EMS did not call a hospital for acceptance, leaving ambulance crews to select an appropriate hospital for emergency care. ${ }^{16}$

\section{Data collection and quality control}

The following data were uniformly collected via regular forms including age, gender, location of call, type of selfharm, temporal patterns and the time course of transportation, destination hospital/department type and patient outcomes. The forms were completed by EMS personnel in cooperation with the physicians caring for the patient, transferred to the EMS Information Center of Osaka Municipal Fire Department and then checked by the investigators. If any data were missing, the investigators returned the form to the relevant EMS personnel for data completion.

\section{Incidence and outcomes}

The study was to evaluate the incidence per 100000 adolescents and their clinical outcomes of emergency selfharm at the scene or on hospital arrival. Outcomes were classified as follows: refusal of transport by patients, only prehospital treatments at the scene, no hospital admission after transportation, hospital admission or death (death confirmed at the scene or death confirmed at the hospital arrival).

\section{Statistical analysis}

Incidence and outcomes of self-harm were compared by the background characteristics and temporal patterns using either $\chi^{2}$ test or Fisher's exact test; outcomes were additionally compared by gender. Incidence of self-harm per 100000 adolescents by age and gender was calculated with the 2010 Osaka census data. ${ }^{14}$ Poisson regression models were applied for incidence trends by age and gender with risk ratios (RRs) and their 95\% CIs were calculated. Time of day was divided into four groups by 6-hour interval. As for season, the period from April to June was defined as spring: first quarter (1Q), July to September summer: second quarter (2Q), October to December autumn: third quarter (3Q) and January to March winter: fourth quarter (4Q), respectively. All statistical analyses were performed using SPSS statistical package V.22.0J (IBM Corp, Armonk, New York, New York, USA). All tests were two-tailed, and $\mathrm{p}$ values of $<0.05$ were considered statistically significant.

\section{RESULTS}

\section{Population}

During the study period, a total of 633359 emergency patients including 18516 adolescents were documented in Osaka City. Of 18516 , a total of 365 adolescents with 425 incidents of self-harm were identified. The youngest boy and girl were 11 and 12 years old, respectively. The incidence per 100000 persons by age and gender is 
shown in figure 1 . The incidence of self-harm increased significantly between the ages of 11 and 19 years, from 6.3 to 81.0 among boys and the ages of 12 and 19 years from 6.3 to 228.3 among girls, respectively (both $\mathrm{p}<0.001)$. The incidence was highest in 19 years old. Although no marked difference in incidence was noted between girls and boys in the group aged 11-14 years (RR 1.20; 95\% CI 0.59 to 2.47), the incidence was significantly higher among girls than boys in the group aged 15-19 years (RR 4.18 ; $95 \%$ CI 3.20 to 5.45 ).

\section{Temporal patterns}

Temporal patterns were described in figure 2. The number of cases by time of day was the lowest at the period of 6-12 hours, and the number was doubled during the period of 18-24 hours (RR 2.12; 95\% CI 1.59 to 2.98). The number was the same between the period of $0-6$ and 12-18 hours (figure 2A). Regarding influence of day of the week, the number did not markedly differ by day (figure 2B). As for seasons, the number was 1.36 times (95\% CI 1.02 to 1.82 ) greater in spring: $1 Q$ (April to June) than in winter: 4Q (January to March; figure 2C).

\section{Characteristics}

Population characteristics by type of self-harm are shown in table 1. A total of 88 (20.7\%) incidents of self-harm were reported among boys, versus 337 (79.3\%) among girls, with an overall mean age of 17.3 years. Proportions of types of self-harm were as follows: $210(49.4 \%)$ cases of poisoning by drugs, $158(37.2 \%)$ cases of cutting skin, $26(6.1 \%)$ cases of jumping from heights, $22(5.2 \%)$ cases of hanging, $6(1.4 \%)$ cases of poisoning by gas and $3(0.7 \%)$ cases of drowning. There was no self-harm by firearms in this area. Locations where self-harm occurred were home $(80.9 \%)$, road $(12.2 \%)$, building $(5.4 \%)$, school $(1.0 \%)$ and healthcare facility $(1.0 \%)$, respectively. The mean time from call to EMS contact and to hospital arrival was 6.5 and $48.6 \mathrm{~min}$, respectively. A total of $54(12.7 \%)$ self-harm cases were transported to critical care medical centres and $289(68.0 \%)$ to noncritical care medical centres, whereas the number of non-transported patients including cases with refusal of

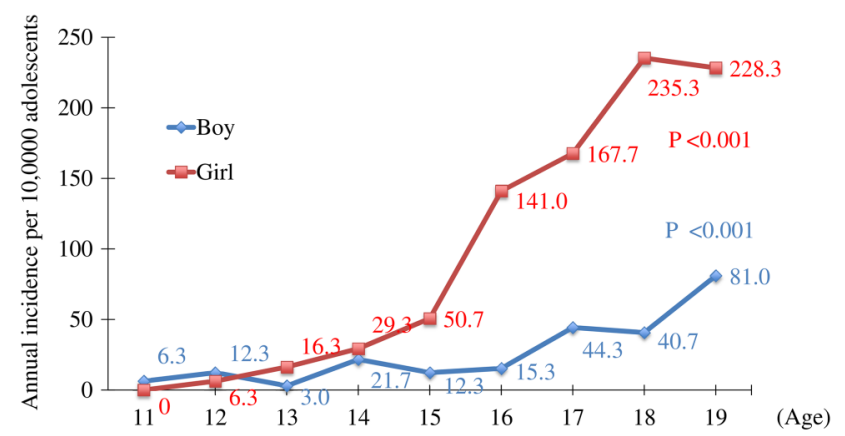

Figure 1 Incidence per 100000 persons of adolescents with emergency self-harm by age and gender. transport by themselves, only prehospital treatments or death confirmed at the scene was $82(19.3 \%)$. Patients transported to medical centres were treated at the following departments: $168(39.5 \%)$ in surgery, 162 $(38.1 \%)$ in internal medicine, $8(1.9 \%)$ in paediatrics and $5(1.2 \%)$ in psychiatry.

\section{Outcomes}

Outcomes by type of self-harm are shown in table 2. A total of $73(17.2 \%)$ patients $(7.1 \%$ transportation
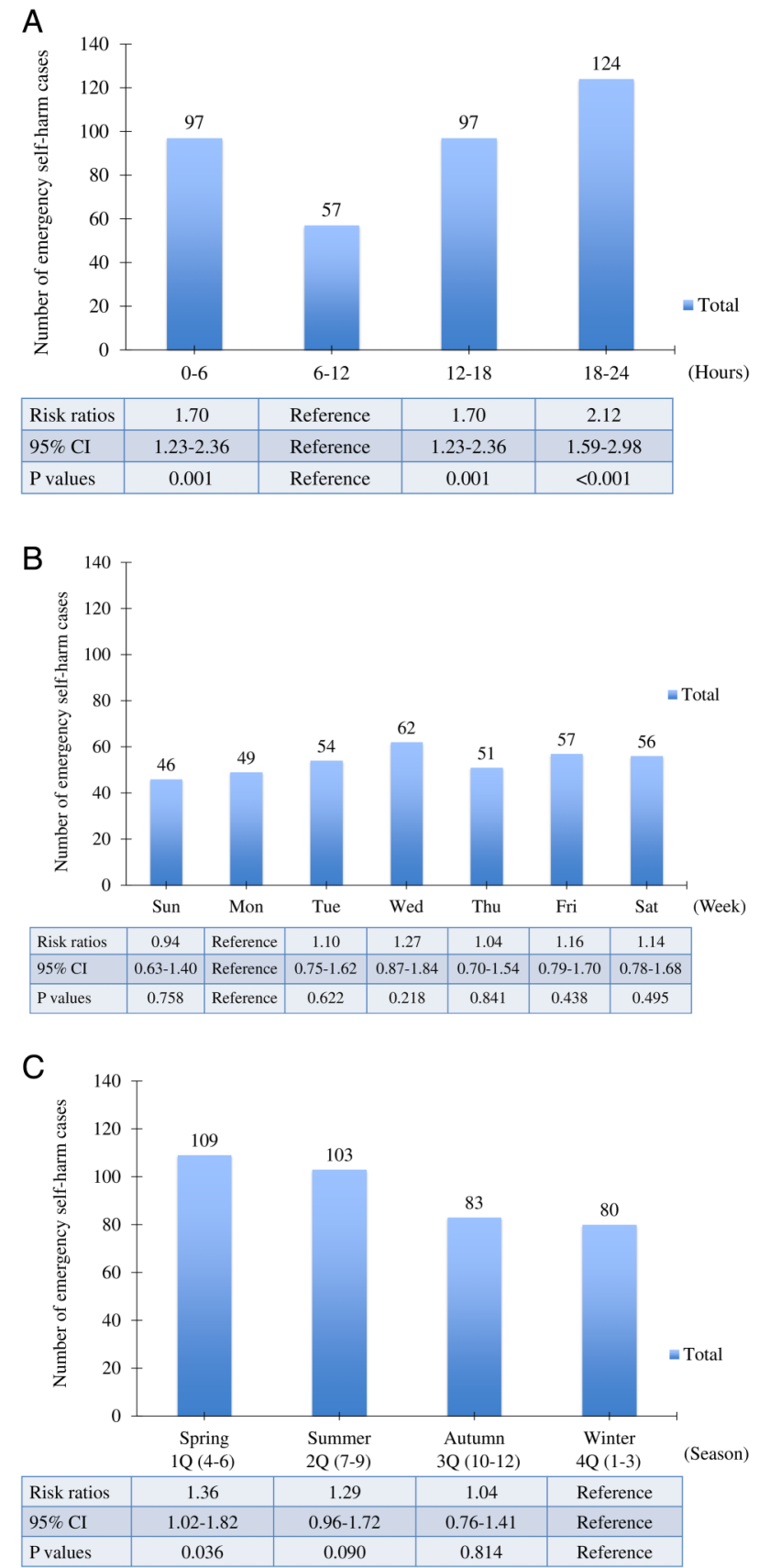

Figure 2 Number of emergency self-harm cases among adolescents by temporal patterns such as $(A)$ hour, (B) week and $(C)$ season. $1 \mathrm{Q}$, first quarter; $2 \mathrm{Q}$, second quarter; $3 \mathrm{Q}$, third quarter; $4 \mathrm{Q}$, fourth quarter. 
Table 1 Characteristics of emergency self-harm among adolescents in Osaka City

\begin{tabular}{|c|c|c|c|c|c|c|c|c|}
\hline & $\begin{array}{l}\text { Total } \\
(\mathrm{n}=425)\end{array}$ & $\begin{array}{l}\text { Poisoning by } \\
\text { drugs } \\
(n=210)\end{array}$ & $\begin{array}{l}\text { Poisoning by } \\
\text { gas } \\
(n=6)\end{array}$ & $\begin{array}{l}\text { Cutting } \\
\text { skin } \\
(\mathrm{n}=158)\end{array}$ & $\begin{array}{l}\text { Jumping from } \\
\text { heights } \\
(n=26)\end{array}$ & $\begin{array}{l}\text { Hanging } \\
(\mathrm{n}=22)\end{array}$ & $\begin{array}{l}\text { Drowning } \\
(\mathrm{n}=3)\end{array}$ & p Values* \\
\hline Boy, n (\%) & $88(20.7)$ & $40(19.0)$ & $5(83.3)$ & $20(12.7)$ & 9 (34.6) & $13(59.0)$ & 1 (33.3) & $<0.001$ \\
\hline Girl, n (\%) & 337 (79.3) & $170(81.0)$ & $1(16.7)$ & $138(87.3)$ & $17(65.4)$ & $9(41.0)$ & $2(66.7)$ & \\
\hline Age, year, n (\%) & & & & & & & & $<0.001$ \\
\hline 11 & $2(0.5)$ & $1(0.5)$ & $0(0.0)$ & $0(0.0)$ & $1(3.8)$ & $0(0.0)$ & $0(0.0)$ & \\
\hline 12 & $6(1.5)$ & $1(0.5)$ & $0(0.0)$ & $2(1.3)$ & $1(3.8)$ & $2(9.1)$ & $0(0.0)$ & \\
\hline 13 & $6(1.5)$ & $5(2.4)$ & $0(0.0)$ & $0(0.0)$ & $0(0.0)$ & $1(4.5)$ & $0(0.0)$ & \\
\hline 14 & $16(4.2)$ & $7(3.3)$ & $0(0.0)$ & $2(1.3)$ & 7 (26.9) & $1(4.5)$ & $0(0.0)$ & \\
\hline 15 & $20(5.2)$ & $12(5.7)$ & $1(16.7)$ & $7(4.4)$ & $1(3.8)$ & $2(9.1)$ & $0(0.0)$ & \\
\hline 16 & 49 (12.9) & $32(15.2)$ & $0(0.0)$ & 21 (13.3) & $1(3.8)$ & $0(0.0)$ & $1(33.3)$ & \\
\hline 17 & 65 (17.1) & 37 (17.6) & $1(16.7)$ & 24 (15.2) & 7 (26.9) & $2(9.1)$ & $2(66.7)$ & \\
\hline 18 & $94(24.7)$ & $57(27.1)$ & $0(0.0)$ & $43(27.2)$ & $4(15.4)$ & $6(27.3)$ & $0(0.0)$ & \\
\hline 19 & $117(30.7)$ & $58(27.6)$ & $4(66.7)$ & 59 (37.3) & $4(15.4)$ & $8(36.4)$ & $0(0.0)$ & \\
\hline Place, n (\%) & & & & & & & & $<0.001$ \\
\hline Home & 344 (80.9) & $183(87.1)$ & $4(66.7)$ & $124(78.5)$ & $11(42.3)$ & $22(100.0)$ & $0(0.0)$ & \\
\hline Road & $52(12.2)$ & $12(5.7)$ & $1(16.7)$ & $22(13.9)$ & $14(53.8)$ & $0(0.0)$ & $3(100)$ & \\
\hline Building & $23(5.4)$ & $10(4.8)$ & $1(16.7)$ & $12(7.6)$ & $0(0.0)$ & $0(0.0)$ & $0(0.0)$ & \\
\hline School & $3(1.0)$ & $2(1.0)$ & $0(0.0)$ & $0(0.0)$ & $1(3.8)$ & $0(0.0)$ & $0(0.0)$ & \\
\hline Healthcare facility & $3(1.0)$ & $3(1.4)$ & $0(0.0)$ & $0(0.0)$ & $0(0.0)$ & $0(0.0)$ & $0(0.0)$ & \\
\hline $\begin{array}{l}\text { Call to contact with a patient by EMS, } \\
\text { min, mean (SD) }\end{array}$ & $6.5(5.0)$ & $6.4(3.1)$ & $7.3(4.0)$ & $6.1(3.1)$ & $6.5(3.0)$ & $7.0(2.2)$ & $33.7(42.0)$ & $<0.001$ \\
\hline $\begin{array}{l}\text { Call to hospital arrival, min, mean (SD)† } \\
\text { Type of hospitals, } n(\%)\end{array}$ & $48.6(25.6)$ & $55.7(27.6)$ & $43.0(17.0)$ & $43.0(20.6)$ & $43.2(23.3)$ & $41.8(30.8)$ & $99.0(0.0)$ & $\begin{array}{l}<0.001 \\
<0.001\end{array}$ \\
\hline No transportation & $82(19.3)$ & $30(14.3)$ & $3(50.0)$ & $38(24.1)$ & $0(0.0)$ & $9(40.9)$ & $2(66.7)$ & \\
\hline Non-critical care medical centre & $289(68.0)$ & 154 (73.3) & $1(16.7)$ & $117(74.1)$ & $9(34.6)$ & $7(31.8)$ & 1 (33.3) & \\
\hline Critical care medical centre & $54(12.7)$ & $26(12.4)$ & $2(33.3)$ & $3(1.9)$ & $17(65.4)$ & $6(27.3)$ & $0(0.0)$ & \\
\hline Type of transported department, $n(\%) \dagger$ & & & & & & & & $<0.001$ \\
\hline Surgery & $168(39.5)$ & $24(11.4)$ & $1(16.7)$ & $108(68.4)$ & $26(100.0)$ & $9(40.9)$ & $0(0.0)$ & \\
\hline Internal medicine & $162(38.1)$ & $145(69.0)$ & $2(33.3)$ & $11(7.0)$ & $0(0.0)$ & $3(13.6)$ & 1 (33.3) & \\
\hline Paediatrics & $8(1.9)$ & $8(3.8)$ & $0(0.0)$ & $0(0.0)$ & $0(0.0)$ & $0(0.0)$ & $0(0.0)$ & \\
\hline Psychiatry & $5(1.2)$ & $3(1.4)$ & $0(0.0)$ & $1(0.6)$ & $0(0.0)$ & $1(4.5)$ & $0(0.0)$ & \\
\hline
\end{tabular}

${ }^{*}$ Comparisons between the six groups were evaluated with Fisher's exact test.

†Calculated only for self-harms transported to institutions.

EMS, emergency medical services. 


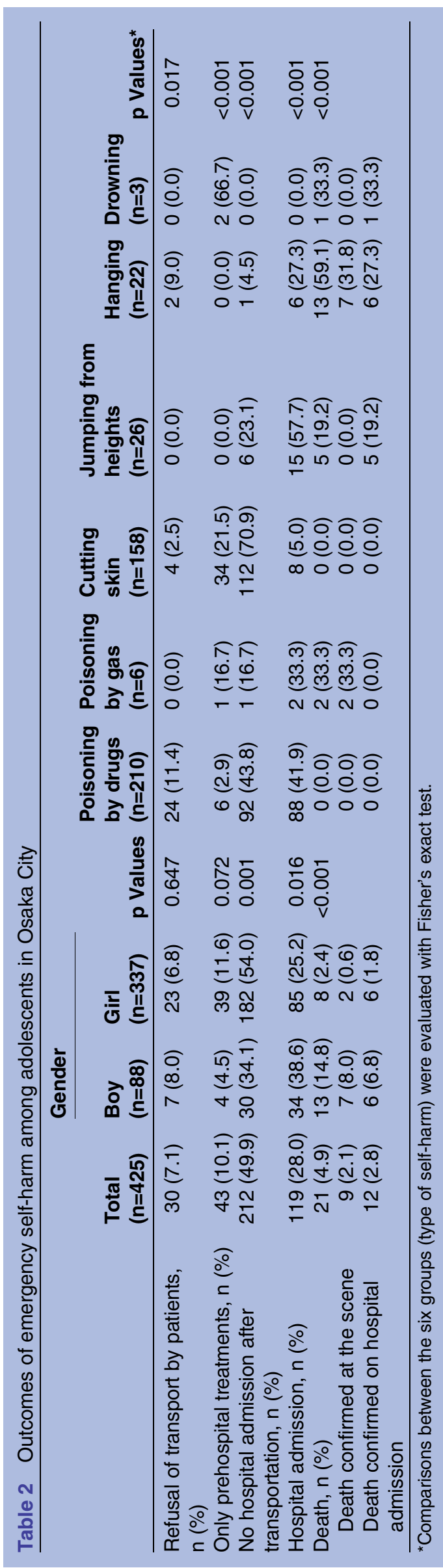

rejection by patients and $10.1 \%$ only prehospital treatment) were not transported to hospitals. About $50 \%$ of adolescents transported to hospitals were only treated at the emergency room but were not admitted to hospitals. Hospital admission was more frequent among boys than among girls $(38.6 \%$ vs $25.2 \%, \mathrm{p}=0.016)$. The proportion of death by self-harm was $4.9 \%$ and was higher for boys than for girls $(14.8 \%$ vs $2.4 \%, \mathrm{p}<0.001)$. As for the type of self-harm, $41.9 \%$ of patients with poisoning by drugs were admitted to hospitals. Most of adolescents with cutting skin $(70.9 \%)$ were not admitted to hospitals. A total of $15(57.7 \%)$ adolescents who harmed themselves by jumping from heights were admitted to hospitals and $5(19.2 \%)$ died. The proportion who died by hanging reached $59.1 \%$. As for poisoning by gas, two patients were admitted to hospitals and two died $(33.3 \%$, respectively).

\section{DISCUSSION}

Here, we conducted a population-based study on adolescents treated for self-harm by EMS personnel by assessing ambulance records in Osaka City, Japan. The incidence of emergency treatment for self-harm by adolescents increased with age and our findings also demonstrated the gender paradox that whereas the incidence was higher among girls than boys, particularly in the group aged $\geq 15$ years, the proportions of deaths were greater among boys. The overall proportion of deaths due to self-harm was $\sim 5 \%$, with values differing by the type of self-harm. Although a number of studies have been conducted on the topic of adolescent selfharm, no other such large-scale evaluations have been conducted using ambulance records in Japan. In addition, to the best of our knowledge, this is the first study to assess EMS-related adolescent self-harm and provides important epidemiological information which may help prevent incidents of self-harm among adolescents in Asia.

Some reports have shown that the incidence of selfharm varied between communities and/or countries. ${ }^{8}$ In this study, $\sim 5 \%$ of total self-harm incidents resulted in death, a value similar to that reported by the WHO in another study. ${ }^{1}$ Most incidents of self-harm manifested as poisoning by drugs or cutting skin in our study, a finding similar to that in a previous report from the USA. ${ }^{17}$ However, some discrepancies were noted in our present findings and those in other similar studies; for example, in the USA, the most frequent manner of death by self-harm is reported to be by firearm, ${ }^{2}$ and this is unlikely to be reported in Japan due to strict firearm regulations. Self-harm-even that performed outside of a suicide attempt-is well known to be a major risk factor for future suicide attempts; as such, ardent efforts should be made to reduce or prevent incidents of self-harm, irrespective of the type. ${ }^{56}$

The youngest participants in this study were aged 11 years, and incidence increased with age among both 
genders, a result consistent with the findings from the preceding studies in western countries. ${ }^{2}{ }^{7}$ This shift in incidence with age may be due to a range of factors, such as increasing prevalence of psychiatric disorders, and the development of cognitive function as well as lifestyle, life events and problems, and social influences. ${ }^{9}{ }^{18-21}$ For example, O'Connor et $a l^{21}$ demonstrated that smoking, drug use, bullying, physical abuse, sexual orientation worries, serious boy/girlfriend problems and self-harm by friends or family were associated with self-harm as lifestyle, life events and problems, and social influences. In addition, the prevalence of psychiatric disorders-one of the important causes of selfharm-dramatically increased during adolescence. ${ }^{18} \quad 19$ Therefore, wide measures with consideration for situations surrounding adolescents and their developmental stage are needed to prevent suicides.

Although no marked difference in incidence was noted between girls and boys aged 11-14 years, incidence was significantly higher among girls than boys aged $\geq 15$ years, possibly due to the high incidence of psychiatric disorders among girls compared with boys. ${ }^{19}$ Puberty in girls is another plausible reason for the high incidence of self-harm. ${ }^{22}$ For example, puberty might cause lack of synchrony between age and cognitive development and be at risk of self-harm. Although boys also go through puberty, female hormones may lead to the increased prevalence of self-harm among girls. ${ }^{23}$ However, while incidence of self-harm was higher in girls than in boys, self-harm by boys more often resulted in hospital admission or death. Although the cause of the increased severity of incidents among boys is unclear, our findings here are consistent with those in the USA. ${ }^{24}{ }^{25}$ Given these present findings and reports of gender differences in the effectiveness of suicide prevention efforts, ${ }^{26}$ gender-specific preventions and interventions should be developed for adolescents who engage in self-harm even in Japan.

To the best of our knowledge, no other studies have investigated the rates of self-harm among adolescents by temporal patterns. In this study, we found that the rate of self-harm was higher in spring months than in winter ones, a finding which concurred with the results in previous studies on adult self-harm. ${ }^{27}{ }^{28}$ With regard to time of day, incidents of self-harm were fewest from 6 to 12 hours, a result consistent with those of a prior study conducted in adults. ${ }^{13}$ However, while a previous study in adults found that the numbers of self-harm incidents were highest on Mondays, we found no significant differences by the day of week in this study. Given these present and previous findings, temporal patterns of selfharm in adolescents seem to be basically similar to those in adults, and our findings could yield fundamental information on improving prevention strategies such as more careful monitoring of children with identified potential risk factors ${ }^{21}$ by parents or school staff based on these temporal patterns in order to reduce the incidence of adolescent self-harm.
Adolescent self-harm is the greatest risk factors for future suicide. ${ }^{16}{ }^{17} \mathrm{~A}$ recent meta-analysis has shown that active interventions among adolescents following an instance of self-harm helped prevent future self-harm and suicide. ${ }^{29}$ Given the effectiveness of active and gender-specific interventions in preceding studies, ${ }^{26} 29$ comprehensive measures of self-harm prevention for adolescents, especially girls, should be taken even in Japan as with the suicide prevention ${ }^{30}$ in cooperation with various organisations.

However, this study has several inherent limitations. First, the data used in this study were based on ambulance records by EMS personnel, and we did not obtain information on the purpose/motivation of self-harm such as suicidal intention, adolescents' comorbidities or history of suicide or self-harm attempt, or outcomes after hospital admissions. At present, we are prospectively collecting data on emergency patients with these data in Osaka Prefecture since 2015 and will address these concerns in future. Second, our study included only emergency patients treated by EMS personnel, and we therefore have no information on walk-ins with selfharm or patients who did not request emergency services, although a previous study demonstrated that the number of patients with self-harm who did not request emergency services is about eight times as large as those who did. ${ }^{31}$ The last important limitation was that we could not detect repeating self-harm in an adolescent, thereby lifetime experience of self-harm might lead to being overestimated from our study.

\section{CONCLUSION}

The incidence of emergency self-harm in adolescents increased with age, and was higher among girls than boys in the group aged $\geq 15$ years. However, the proportion of hospital admissions and death due to self-harm was greater among boys than among girls. It would be necessary to establish active, gender-specific and comprehensive prevention strategies for adolescent self-harm, based on our findings showing the age and gender differences of self-harm among adolescents.

Author affiliations

${ }^{1}$ Department of Emergency Medicine, Kyoto Prefectural University of Medicine, Kyoto, Japan

${ }^{2}$ Division of Environmental Medicine and Population Sciences, Department of Social and Environmental Medicine, Graduate School of Medicine, Osaka University, Suita, Japan

${ }^{3}$ Department of Public Health, Tokyo Women's Medical University, Tokyo, Japan

${ }^{4}$ Osaka Municipal Fire Department, Osaka, Japan

${ }^{5}$ Department of Emergency Medicine, Osaka Medical College, Takatsuki, Japan ${ }^{6}$ Department of Pediatrics, Osaka Medical College, Takatsuki, Japan

${ }^{7}$ Kyoto University Health Services, Kyoto, Japan

Acknowledgements The authors are greatly indebted to all of the EMS personnel at the Osaka Municipal Fire Department and the concerned physicians in Osaka City for their indispensable cooperation and support.

Contributors TM, TKi, SH, MN and TI conceived and designed the study. TM, TKi, KK and TKa analysed the data. TM, TKi and BO wrote the paper. 
Funding This research received no specific grant from any funding agency in the public, commercial or not-for-profit sectors.

Competing interests None declared.

Ethics approval This study was approved by the Ethics Committee of Kyoto University Graduate School of Medicine and the Ethics Committee of Kyoto Prefectural University of Medicine.

Provenance and peer review Not commissioned; externally peer reviewed.

Data sharing statement TM and TKi had full access to all of the data in the study and take responsibility for the integrity of the data and the accuracy of the data analysis.

Open Access This is an Open Access article distributed in accordance with the Creative Commons Attribution Non Commercial (CC BY-NC 4.0) license, which permits others to distribute, remix, adapt, build upon this work noncommercially, and license their derivative works on different terms, provided the original work is properly cited and the use is non-commercial. See: http:// creativecommons.org/licenses/by-nc/4.0/

\section{REFERENCES}

1. World Health Organization. Mental health: Suicide Prevention. http://www.who.int/mental_health/suicide-prevention/en/ (accessed 30 May 2015).

2. Centers for Disease Control and Prevention. Violence prevention: Suicide. http://www.cdc.gov/violenceprevention/suicide/index.html (accessed 30 May 2015).

3. Ministry of Health, Labour and Welfare. Specified Report of Vital Statistics: Age-Adjusted Death Rates by suicides (Japanese). http://www.mhlw.go.jp/toukei/saikin/hw/jinkou/tokusyu/suicide04/ (accessed 30 May 2015).

4. National Institutes of Health. Health \& Education: Suicide Prevention. http://www.nimh.nih.gov/health/topics/suicide-prevention/ index.shtml (accessed 30 May 2015).

5. Hawton K, Fagg J. Suicide, and other causes of death, following attempted suicide. Br J Psychiatry 1988;152:359-66.

6. Brent DA, Perper JA, Moritz G, et al. Suicide in affectively ill adolescents: a case-control study. J Affect Disord 1994;31:193-202.

7. Hawton K, Harriss L, Hall S, et al. Deliberate self-harm in Oxford, 1990-2000: a time of change in patient characteristics. Psychol Med 2003;33:987-95.

8. Owens D, Horrocks J, House A. Fatal and non-fatal repetition of self-harm: systematic review. Br J Psychiatry 2002;181:193-9.

9. Nock MK, Green JG, Hwang I, et al. Prevalence, correlates, and treatment of lifetime suicidal behavior among adolescents: results from the National Comorbidity Survey Replication Adolescent Supplement. JAMA Psychiatry 2013;70:300-10.

10. Zoroglu SS, Tuzun U, Sar V, et al. Suicide attempt and self-mutilation among Turkish high school students in relation with abuse, neglect and dissociation. Psychiatry Clin Neurosci 2003;57:119-26.

11. Cerutti R, Manca M, Presaghi F, et al. Prevalence and clinical correlates of deliberate self-harm among a community sample of Italian adolescents. J Adolesc 2011;34:337-47.

12. Niigata City. Epidemiology of suicide attempts in Niigata City (Japanese). http://www.city.niigata.lg.jp/iryo/kokoro/jisatsu/ jittaihaaku.html (accessed 30 May 2015).
13. Toyoda $\mathrm{Y}$, Nakayama A, Fujiwara $\mathrm{H}$, et al. Characteristics of suicides according to prehospital records in Kishiwada City, Osaka Prefecture. Nihon Koshu Eisei Zasshi 2008;55:247-53. (In Japanese).

14. Japan Statistical Association. 2010 Population Census of Osaka-city (Japanese). http://www.city.osaka.Ig.jp/shisei_top/category/ 1756-0-0-0-0.html (accessed 30 May 2015).

15. Iwami T, Nichol G, Hiraide A, et al. Continuous improvements of chain of survival increased survival after out-of-hospital cardiac arrests: a large-scale population-based study. Circulation 2009;119:728-34.

16. Osaka Municipal Fire Department. 2013 Emergency Annual Statistics. Osaka: Osaka-Shi Shoubo (Japanese). http://www.city. osaka.lg.jp/shobo/page/0000267911.html (accessed 30 May 2015).

17. Doshi A, Boudreaux ED, Wang N, et al. National study of US emergency department visits for attempted suicide and self-inflicted injury, 1997-2001. Ann Emerg Med 2005;46:369-75.

18. Costello EJ, Mustillo S, Erkanli A, et al. Prevalence and development of psychiatric disorders in childhood and adolescence. Arch Gen Psychiatry 2003;60:837-44.

19. Merikangas KR, He J-P, Burstein M, et al. Lifetime prevalence of mental disorders in U.S. adolescents: results from the National Comorbidity Survey Replication-Adolescent Supplement (NCS-A). J Am Acad Child Adolesc Psychiatry 2010;49:980-9.

20. Shaffer D, Gould MS, Fisher P, et al. Psychiatric diagnosis in child and adolescent suicide. Arch Gen Psychiatry 1996;53:339-48.

21. O'Connor RC, Rasmussen S, Miles J, et al. Self-harm in adolescents: self-report survey in schools in Scotland. $\mathrm{Br} J$ Psychiatry 2009;194:68-72.

22. Graber JA, Seeley JR, Brooks-Gunn J, et al. Is pubertal timing associated with psychopathology in young adulthood? J Am Acad Child Adolesc Psychiatry 2004;43:718-26.

23. Mousavi SG, Bateni S, Maracy MR, et al. Recurrent suicide attempt and female hormones. Adv Biomed Res 2014;3:201.

24. Brent DA, Baugher M, Bridge J, et al. Age- and sex-related risk factors for adolescent suicide. J Am Acad Child Adolesc Psychiatry 1999;38:1497-505.

25. Spicer RS, Miller TR. Suicide acts in 8 states: incidence and case fatality rates by demographics and method. Am J Public Health 2000;90:1885-91.

26. Hamilton E, Klimes-Dougan B. Gender differences in suicide prevention responses: implications for adolescents based on an illustrative review of the literature. Int J Environ Res Public Health 2015;12:2359-72.

27. Woo J-M, Okusaga O, Postolache TT. Seasonality of suicidal behavior. Int J Environ Res Public Health 2012;9:531-47.

28. Bridges FS, Yip PS, Yang KC. Seasonal changes in suicide in the United States, 1971 to 2000. Percept Mot Skills 2005; 100:920-4.

29. Inagaki M, Kawashima $\mathrm{Y}$, Kawanishi $\mathrm{C}$, et al. Interventions to prevent repeat suicidal behavior in patients admitted to an emergency department for a suicide attempt: a meta-analysis. $J$ Affect Disord 2015;175:66-78.

30. Cabinet Office, Government of Japan. 2015 White paper on Suicide Prevention in Japan (Japanese). http://www8.cao.go.jp/ jisatsutaisaku/whitepaper/en/w-2015/summary.html (accessed 20 Apr 2016).

31. Madge N, Hewitt A, Hawton K, et al. Deliberate self-harm within an international community sample of young people: comparative findings from the Child \& Adolescent Self-harm in Europe (CASE) Study. J Child Psychol Psychiatry 2008;49:667-77. 